\title{
O ESTADO DA ARTE DAS EXPERIÊNCIAS DE PESQUISAS APRESENTADAS NO GRUPO DE TRABALHO DESENVOLVIMENTO REGIONAL E INFRAESTRUTURA DO XI ENANPEGE (2015)
}

\author{
State of the art of research experiences submitted \\ the working group regional development \\ and infrastructure of Enanpege XI (2015)
}

Estado del arte técnica de experiencias de investigación presentadas grupo de trabajo desarrollo regional y de infraestructura de XI Enanpege (2015)

\section{Pierre Alves Costa}

Doutorado em História pela Universidade Federal Fluminense. Docente no Programa de Pós-graduação em Geografia da Universidade Estadual do Centro-Oeste (PR). Universidade Estadual do Centro-Oeste (PR), Departamento de Geografia. Rua Simeão Camargo Varela de Sá, 03 - Vila Carli| CEP 85040-080 Fone: (42) 3629-8117 Guarapuava - PR.

E.mailalvespierre75@hotmail.com

\section{Lisandra Pereira Lamoso}

Doutorado em Geografia Humana pela Universidade de São Paulo. Docente no Programa de Pósgraduação em Geografia da Universidade Federal da Grande Dourados (UFGD). Universidade Federal da Grande Dourados, Faculdade de Ciências Humanas, Rodovia Dourados Itahum, km12, Cidade Universitária.79825-070 - Dourados-MS. E.maillisandralamoso@ufgd.edu.br

\section{RESUMO}

O presente artigo reflete o estado da arte dos trabalhos apresentados no Grupo de Trabalho (GT) "Desenvolvimento Regional e Infraestrutura", ocorrido no XI Encontro Nacional da Associação Nacional de Pós-graduação e Pesquisa em Geografia, na cidade de Presidente Prudente (SP), no período de 09 a 12 de outubro de 2015. Os trabalhos estiveram distribuídos em cinco eixos centrais: 1) Circulação, transportes e logística; 2) Financeirização do território nacional; 3) Políticas públicas e desenvolvimento regional; 4) Desenvolvimento econômico, política industrial e comércio exterior; 5) Agronegócio e circuitos espaciais da produção. O intuito é demonstrar as análises realizadas pelos coordenadores. Para a construção do mesmo, foram feitas as seguintes etapas: definição de eixos e critérios de avaliação; análise dos resumos e trabalhos completos; balanço crítico das apresentações e debates ocorridos ao longo do GT. Por fim, por ser uma atividade difícil e complexa, o Estado da arte detém caráter crítico e reflexivo; contribuindo, dessa forma, no desenvolvimento de novas demandas de pesquisa, conceitos e paradigmas.

Palavras-chave: Estado da Arte; Desenvolvimento Regional e Infraestrutura; Produção Acadêmica. 


\begin{abstract}
This article reflects the state of the art works presented in the Working Group (WG) "Regional Development and Infrastructure", occurred in XI National Meeting of the National Association of Graduate Studies and Research in Geography, in the city of Presidente Prudente (SP), the period of 09 the 12 October 2015. The works were divided into five core areas: 1) Circulation, transport and logistics; 2) Financialization of the national territory; 3) Public policies and regional development; 4) Economic development, industrial policy and foreign trade; 5) Agribusiness and spatial production circuits. The aim is to demonstrate the analysis carried out by the coordinators. For the construction thereof, the following steps were taken: setting priorities and evaluation criteria; analysis of abstracts and full papers; critical assessment of the presentations and discussions that took place throughout the GT. Finally, because it is a difficult and complex activity, the state of the art has critical and reflective character; thereby contributing in the development of new research demands, concepts and paradigms.
\end{abstract}

Keywords: State of the art; Regional Development and Infrastructure; Academic Production.

\title{
RESUMEN
}

Este artículo refleja el estado del arte dos trabajos presentados en el Grupo de Trabajo (GT) "Desarrollo Regional e Infraestructura" celebrado en el XI Encuentro Nacional de la Asociación Nacional de Estudios Graduados e Investigación en Geografía, en la ciudad de Presidente Prudente (SP), el período del 09 a 12 de octubre del año 2015. Los trabajos se dividen en cinco áreas principales: 1) La circulación, el transporte y la logística; 2) mercantilización de parte del territorio nacional; 3) Las políticas públicas y el desarrollo regional; 4) El desarrollo económico, la política industrial y el comercio exterior; 5) Agroindustria y circuitos de producción espaciales. El objetivo es demostrar el análisis llevado a cabo por los coordinadores. Para la construcción del mismo, se tomaron las siguientes etapas: definición de ejes y criterios de evaluación; análisis de los resúmenes y trabajos completos; evaluación crítica de las presentaciones y discusiones que tuvieron lugar a lo largo del GT. Finalmente, debido a que es una actividad difícil y complejo, el estado de la técnica tiene carácter crítico y reflexivo; contribuyendo de esta manera en el desarrollo de nuevas investigaciones demandas, conceptos y paradigmas.

Palabras clave: Estado del Arte; Desarrollo Regional y de Infraestructura; Producción Académica. 


\section{INTRODUÇÃO}

A temática do Desenvolvimento Regional e Infraestruturas se coloca necessária pelas características atuais do processo de desenvolvimento brasileiro, pautado: no fortalecimento da intervenção do Estado, retomada da elaboração de políticas públicas e dos investimentos em infraestruturas, novos modelos regulatórios para a concessão dos serviços públicos, a atuação das corporações e seu papel na internacionalização da produção. São temas pertinentes à discussão sobre o desenvolvimento regional brasileiro, suas repercussões, conflitos de interesses, embate capital x trabalho e o papel do Brasil na divisão internacional do trabalho. Este Grupo de Trabalho tem origem na discussão acumulada pelo Grupo de Estudos em Desenvolvimento Regional e Infraestruturas (GEDRI), em funcionamento desde o ano de 2005 e do Grupo de Estudos da Dinâmica Econômica, desde 2008.

O GT foi proposto pelos professores Fábio Betioli Contel (USP), Lisandra Pereira Lamoso (UFGD), Márcio Rogério Silveira (UFSC), Pierre Alves Costa (UNICENTRO), João Márcio Palheta (UFPA) e Aloysio Marthins de Araújo Junior (UFSC) e os trabalhos foram aglutinados em cinco eixos de pesquisa:

- Circulação, transportes e logística;

- Financeirização do território nacional;

- Políticas públicas e desenvolvimento regional;

- Desenvolvimento econômico, política industrial e comércio exterior;

- Agronegócio e circuitos espaciais da produção.

Um dos resultados obtidos após a apresentação/debate dos trabalhos foi a socialização das experiências de pesquisa, reunião de um acervo qualificado com desdobramentos para a qualificação da pós-graduação e efetiva contribuição ao debate nacional.

\section{RELEVÂNCIA DO ESTADO DA ARTE PARA A PESQUISA}

Nos últimos trinta anos tem se gerado um acervo expressivo de estudos designados

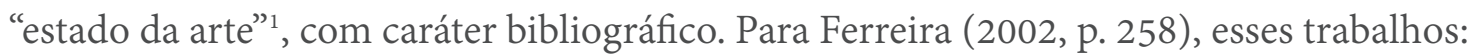

Parecem trazer em comum o desafio de mapear e de discutir uma certa produção acadêmica em diferentes campos do conhecimento, tentando responder que aspectos e dimensões vêm sendo destacados e privilegiados em diferentes épocas e lugares, de que formas e em que condições têm sido produzidas certas dissertações de mestrado, teses de doutorado, publicações em periódicos e comunicações em anais de congressos e de seminários.

\footnotetext{
Também denominadas de "estado do conhecimento".
} 
O “estado do conhecimento" também é valorizado por adotarem uma metodologia de aspecto inventariante e descritivo em referência à produção científica a respeito da temática que almeja inquiri, "à luz de categorias e facetas que se caracterizam enquanto tais em cada trabalho e no conjunto deles, sob os quais o fenômeno passa a ser analisado". (FERREIRA, 2002, p. 258).

Outra pesquisadora que também chama a atenção da relevância dos estudos sobre o "estado da arte" é Alves-Mazzotti (2006). Para a autora, é indispensável confeccionar uma revisão crítica de estudos e teorias no processo de geração de novos conhecimentos, para demonstrar inadequações nos modos de tratar as questões com que se depara a ciência no Brasil.

Concordamos com Haddad (2002, p. 9), que afirma que as pesquisas do "estado do conhecimento":

Permitem, num recorte temporal definido, sistematizar um determinado campo de conhecimento, reconhecer os principais resultados da investigação, identificar temáticas e abordagens dominantes e emergentes, bem como lacunas e campos inexplorados abertos à pesquisa futura.

Neste artigo, procuramos trilhar no desenvolvimento apontado acima por Haddad, referente aos vinte e oito trabalhos apresentados e debatidos no Grupo de Trabalho (GT) "Desenvolvimento Regional e Infraestrutura". Ademais, compartilhamos da ideia de Barreto e Pinto (2001, p. 5-6) ao argumentarem que:

Com os avanços da informática, a seleção de fontes tem podido contar com os bancos de dados existentes, cuja sistematização regular de informações possibilita maior abrangência do levantamento; se, de um lado, eles ampliam o universo contemplado, de outro, armazenam os dados de forma resumida, o que deve ser levado em conta ao se utilizar tais fontes, pois nem sempre os resumos disponibilizam as informações básicas necessárias para análise $O$ ideal, nesses casos, seria o exame dos textos originais, ainda que se admita a dificuldade de acesso a eles.

Quando não se dispõe de banco de dados, o próprio processo de elaboração dos estados do conhecimento tem levado à organização desses bancos.

Acrescentando, observamos que os estudiosos utilizam como fontes basilares de referência para fazer o levantamento dos dados e suas análises, essencialmente, os catálogos de universidades, faculdades, institutos, associações nacionais (no nosso caso a ANPEGE) e órgãos de fomento à pesquisa.

Esse tipo de divulgação passa a ser confeccionado satisfazendo ao anseio expresso pelas universidades de revelar sua produção à comunidade científica e à sociedade; socializando e ademais, colocando-se à avaliação. Concordamos com Ferreira (2002, p. 260) que diz 
que é uma manifestação que obras geradas ao longo do tempo não devem ficar "presas" às prateleiras das bibliotecas das instituições de ensino superior.

Não obstante, é uma reivindicação imposta por uma sociedade que concebe a universidade como prestadora de serviços e que, portanto, deve ser aquilatada. Conforme Chauí (199, p. 6), a avaliação de toda e qualquer universidade passa a ser determinada por uma qualidade que oferece como definição:

'qualidade' é definida como competência e excelência cujo critério é o atendimento às necessidades de modernização da economia e desenvolvimento social; e é medida pela produtividade, orientada por três critérios: quanto uma universidade produz, em quanto tempo produz e qual o custo do que produz. (...) Observa-se que a pergunta pela produtividade não indaga o que se produz, como se produz, para quem ou para que se produz, mas opera uma inversão tipicamente ideológica da qualidade em quantidade.

Logo, é nesse contexto que os catálogos procuram responder às demandas internas da universidade, como também à pressão externa de uma política reguladora e controladora da produção acadêmica.

\section{ANÁLISE DOS DADOS}

Ressaltamos que foram 49 resumos enviados; e, 44 foram aprovados. Trinta e cinco trabalhos foram enviados e publicados nos Anais. Desses 28 foram apresentados e debatidos; os quais serão o foco de análise do nosso "estado da arte". Os elementos presentes no quadro 1 representam a cartografia das pesquisas baseadas na temática do Desenvolvimento Regional e Infraestrutura. As vinte e oito pesquisas apresentadas e sabatinadas foram classificados em cinco eixos: 1) Circulação, transportes e logística; 2) Financeirização do território nacional; 3) Políticas públicas e desenvolvimento regional; 4) Desenvolvimento econômico, política industrial e comércio exterior; 5) Agronegócio e circuitos espaciais da produção. Observamos que não classificamos nenhum estudo especificamente no eixo 5. Acreditamos que trabalhos voltados para essa temática tenham sido submetidos ao GT "Formações Socioespaciais: progresso técnico no espaço urbano e agrário" - também voltado (como o nosso) para a subárea da Geografia Econômica. 
Quadro 1. Síntese dos trabalhos apresentados no Grupo de Trabalho "Desenvolvimento Regional e Infraestrutura" do XI Encontro Nacional da ANPEGE - Presidente Prudente - 2015.

\section{Título}

\section{Eixos de Pesquisa}

1. Banco comunitário União Sampaio e moeda Sampaio: para além dos serviços financeiros no lugar
Financeirização do território nacional

\section{Instituição \\ Cidade/Estado/ Região}

\section{Nível da pesquisa}

Mestrado concluído

\section{Palavras-chaves}

Bancos Comunitários: Moedas Locais; Lugar
2. Bancos públicos estaduais e o

desenvolvimento regional: topologia Financeirização do território

bancária e geografia do crédito - o caso do nacional

USP São Paulo/SP/SE

COnclullo

Banestes (ES)

3. O papel das normas na topologia dos bancos de investimento no Brasil: do caráter regional à ação verticalizada
Financeirização do território nacional
USP

São Paulo/SP/SE

Mestrado em andamento

Topologia bancária; Geografia do Crédito; Banco Estadual; Banestes

4. Território e Finanças em Alagoas: a influência da folha de pagamentos (FOPAG) das prefeituras na topologia do
Financeirização do território

nacional
USP

São Paulo/SP/SE
Mestrado em andamento
Topologia bancária,

Mestrado concluído conteúdos normativos do território, bancos de investimento

Território; Economia do Setor Público; Alagoas; Prefeituras; FOPAG

Banco do Brasil

5. Automação e emprego bancário: elementos para o debate
Financeirização do território nacional
USP São Paulo/SP/SE
Integração eletrônica do território; Automação

Mestrado em andamento Bancária; Concentração

Bancária; Emprego Bancário; Trabalho Bancário

6. Novos paradoxos da Periferia Paulistana:

da chegada das infraestruturas e da Financeirização do território

Financeirização à permanência da pobreza nacional USP São Paulo/SP/SE

Pós-Doutorado Periferia, pobreza, e da precariedade

7. BNDES, internacionalização de empresas Políticas públicas e brasileiras e integração regional
BNDES; Internacionalização produtiva; Integração regional 

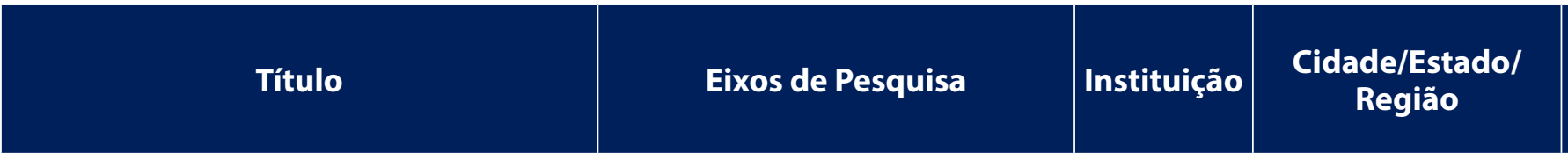

8. Desconexão portuária: uma análise das dificuldades de integração territorial da BR070 nos trechos goiano e mato-grossense

9. O complexo portuário do Itajaí: o papel das políticas institucionais, dos investimentos em infraestrutura e logística na dinâmica de movimentação de cargas
Circulação, transportes e logística;

Políticas públicas e

desenvolvimento regional
Nível da pesquisa

\section{Palavras-chaves}

BR-070; goiano e matogrossense; integração regional; portuária

Complexo Portuário,

transporte e logística,

investimentos em

infraestruturas de transporte

setor portuário, transporte

10. O setor portuário de Sergipe: o caso do terminal marítimo Inácio Barbosa (TMIB), em Barra dos Coqueiros/SE

Circulação, transportes e logística;

Políticas públicas e
desenvolvimento regional

UFS São Cristóvão/SE/NE Docente maritimo, desenvolvimento econômico

11. Integração Regional e diferenciação espacial: uma análise do papel da BR-060 no Centro-Oeste brasileiro

Circulação, transportes e logística;

Políticas públicas e

desenvolvimento regional

Circulação, transportes e logística

12. Política de concessão rodoviária de Mato Grosso do Sul: uma análise do processo de implantação do programa estadual de concessões rodoviárias

13. As seletividades dos projetos de ampliação das infraestruturas de transporte público no estado de São Paulo

14. Contradições entre os sistemas de transporte público, os padrões de mobilidade e a estruturação do espaço na Região Metropolitana de Florianópolis
Circulaçăo, transportes elogística;

Políticas públicas e
desenvolvimento regional

Circulação, transportes e logística;

Políticas públicas e
desenvolvimento regional

Circulação, transportes e logística;

Políticas públicas e

UFSC Florianópolis/SC/S

desenvolvimento regional

UFG Goiânia/GO/CO $\begin{gathered}\text { Doutorado em } \\ \text { andamento }\end{gathered}$

Rodovia BR-060; Dinâmica

territorial; Legendas espaciais 
Título

\section{Eixos de Pesquisa}

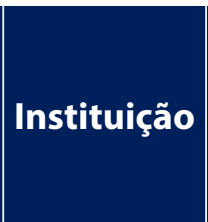

15. Comércio exterior e o sistema de transporte ferroviário: análise comparativa entre o Brasil e o Canadá

16. Controle e tributação das operações de comércio internacional no Brasil: aduanas e territorialidade fiscal a partir das fronteiras

17. Logística territorial: comportamentos e
limitações de Uberlândia/MG

18. Dinâmica econômica e territorial na aglomeração urbana do sul do Rio Grande do Sul (AUSUL): o comércio em Rio Grande (RS)

19. Fluxos de comércio exterior no Brasil e no estado de São Paulo (1999-2014) e a crise financeira de 2008

\section{Financiamento do desenvolvimento brasileiro}

21. O processo de integração sulamericana através da IIRSA/COSIPLAN: uma desenvolvimento regional; discussão a partir do eixo de Capricórnio Circulação, transportes e logística
Circulação, transportes e logística;
Desenvolvimento econômico, política industrial e comércio exterior

\section{Cidade/Estado/ Região}

Circulação, transportes e logística;

Desenvolvimento econômico,

política industrial e comércio exterior

Circulação, transportes e logística;

Políticas públicas e desenvolvimento regional

Políticas públicas e

desenvolvimento regional;

Circulação, transportes e logística

Desenvolvimento econômico, política industrial e comércio exterior

Políticas públicas e desenvolvimento regional;

Políticas públicas e

Circulação, transportes e logística;
UFSC

Florianópolis/SC

Doutorado em Ferrovias, Brasil, Canadá, andamento exportação
Palavras-chaves
UNILA Foz do Iguaçu/PR/S Docente Comércio Internacional; Tributação; Circulação e logística

Logística Urbana.

UFU Uberlândia/MG/SE $\begin{gathered}\text { Mestrado em } \begin{array}{l}\text { Logística Urbana. } \\ \text { andamento }\end{array} \\ \text { Uberlândia. Geografia dos }\end{gathered}$
Transportes 


\section{Título}

22. Um olhar político sobre a usina Hidrelétrica de Belo Monte

23. A imigração para o Norte- Fluminense, Rio de Janeiro, Brasil: configuração dos fluxos migratórios recentes (2000-2010)
Desenvolvimento econômico, política industrial e comércio exterior

\section{Eixos de Pesquisa}

\section{Instituição}

UNESP-RC

\section{Cidade/Estado/ Região}

Nível da pesquisa

Políticas públicas e desenvolvimento regional

\section{Palavras-chaves}

Desenvolvimento; Belo Monte; mobilização popular

Petrobras, Porto do

JFF-PUCG Campos dos Mestrado em Açu, Imigrantes, Norte Goitacazes/RJ/SE andamento Fluminense, Grandes empreendimentos

Desenvolvimento econômico, política industrial e comércio

UFMG Belo Horizonte/MG/ SE

\section{Doutorado em Mobilidade pendular;} andamento rodovias; Minas Gerais

Geografia da Inovação;

Políticas públicas e

UNICAMP Campinas/SP/SE

Doutorado em Sistemas Regionais de andamento Inovação; UniversidadeEmpresas inovação: o caso de Campinas (SP)

Empresas

26. Inovação e difusão: evolução tecnológica do setor cerâmico brasileiro a partir da transferência de tecnologia européia

Desenvolvimento econômico, política industrial e comércio exterior

$\begin{array}{lll}\text { UFSC Florianópolis/SC/S } & \begin{array}{c}\text { Doutorado em } \\ \text { andamento }\end{array} & \begin{array}{l}\text { inovação; transferência de } \\ \text { tecnologia; setor cerâmico } \\ \text { brasileiro }\end{array}\end{array}$

27. A configuração territorial da indústria petrolífera instalada na bacia Potiguar: uma análise a partir dos campos de produção e sistemas técnicos da Petrobras

\section{Desenvolvimento econômico,} política industrial e comércio exterior
UECE Fortaleza/CE/NE

Mestrado em andamento
Configuração Territorial; Indústria Petrolífera; Bacia Potiguar
28. Concretude territorial e regulação híbrida: a política de conteúdo local no setor de exploração e produção de petróleo e gás

\section{Políticas públicas e} desenvolvimento regional
UNICAMP Campinas/SP/SE
Mestrado em andamento
Regulação do território, Conteúdo Local, Petróleo e Gás Natural

Fonte: Anais do XI Encontro Nacional da ANPEGE, 2015.

Org.: Os autores. 
Continuando a análise do quadro 1, observamos que, numa divisão regional foram apresentados trabalhos oriundos das seguintes regiões: Sudeste (16), Sul (7), Centro-Oeste (3) e Nordeste (2). Portanto, não foi apresentado nenhum trabalho oriundo da região Norte. Em relação ao nível da pesquisa, temos a seguinte radiografia (ressaltamos que todos os trabalhos estão relacionados à Universidades Públicas):

- Docentes: 3 pesquisas;

- Pós-Doutorado em andamento: 1 trabalho;

- Doutorado concluído: 1 estudo;

- Doutorado em andamento: 9 pesquisas;

- Mestrado concluído: 2 trabalhos;

- Mestrado em andamento: 12 estudos;

Portanto, os dois níveis de pesquisa com maior representação no GT são: Mestrado em andamento, com 12 trabalhos (48,86\%); e Doutorado em andamento, com 9 estudos $(32,14 \%)$; totalizando 21 pesquisas $(75 \%)$ do total de 28 .

Ademais, somente 2 pesquisas não estão vinculadas a Programas de Pós-Graduação em Geografia. Sendo de um docente vinculado ao Departamento de Geografia da Universidade Federal de Sergipe (Campus de São Cristóvão). E a outra de um docente vinculado ao Programa de Políticas Públicas e Desenvolvimento da Universidade Federal da Integração Latino-Americana (UNILA). As Universidades representadas no GT (com 2 ou mais estudos), por ordem decrescente do número de pesquisas são (as demais tiveram apenas um trabalho apresentado) - vide quadro 1/coluna instituição:

1. Universidade de São Paulo: 7;

2. Universidade Federal de Santa Catarina: 5;

3. Universidade Estadual Paulista - Presidente Prudente: 2;

4. Universidade Estadual Paulista - Rio Claro: 2;

5. Universidade Estadual de Campinas: 2;

6. Universidade Federal de Goiás: 2;

Começaremos a análise qualitativa pelo eixo 2 "Financeirização do território nacional", o qual teve seis trabalhos apresentados. Estas pesquisas versaram primordialmente sobre: o sistema financeiro e bancário nacionais, topologia bancária; relacionado com suas influências sobre os territórios, regiões e a sociedade brasileiros. Os estudos destacam (ver os trabalhos de 1 a 6 do quadro 1): 
- A importância dos bancos e moedas comunitárias;

- A inclusão de milhões de brasileiros no sistema bancário nacional, a partir de 2003, com a criação da conta cidadão da Caixa Econômica Federal (CEF). Este tipo de conta não necessita de comprovação de renda e foi lançado pelo Governo Luiz Inácio da Silva (2003 - 2010);

- A relevância dos ainda existentes bancos públicos estaduais; os quais possuem uma relação muito mais orgânica com o território, em relação aos bancos privados. Como exemplo, observamos o impacto da presença da sede do banco na rede urbana do seu estado; com seu desdobramento em serviços corporativos (ou setor quaternário da economia);

- A centralidade dada aos bancos de investimento para o desenvolvimento do mercado de crédito e de capitais no país associada ao papel de comando das metrópoles;

- A formação dos conglomerados bancários, por meio dos bancos múltiplos;

- As relações dos bancos com a economia do setor público;

- A automação bancária - ocasionando uma reorganização espacial do sistema bancário nacional - e refletindo numa mudança qualitativa e quantitativa no emprego bancário a partir dos anos 1990;

- A crescente expansão do consumo de massa entre as camadas de baixa renda tem implicado, em realidade, o avanço do endividamento e da inadimplência entre esse estrato da população. Renovam-se, assim, os mecanismos que permitem a conformação deste cenário paradoxal de expansão do consumo e reprodução da pobreza;

- A importância da linha de financiamento BNDES Exim Pós-Embarque no suporte à realização de obras de infraestrutura na América Latina e seus impactos territoriais (exportações de bens e serviços).

A respeito dos demais 3 eixos (Circulação, transportes e logística; Políticas públicas e desenvolvimento regional; e, Desenvolvimento econômico, política industrial e comércio exterior) optamos por analisarmos juntos; pois, dos 21 outros estudos, 12 foram classificados em dois eixos concomitantemente (ver quadro 1 - eixos de pesquisa). A seguir, apontaremos principais destaques dos mesmos:

- O Banco Nacional de Desenvolvimento Econômico e Social (BNDES) teve fundamental importância na organização do território e na consolidação do capitalismo industrial brasileiro. Ademais, recentemente, o banco passou a desempenhar um papel internacional relevante, sobretudo na América Latina e na África, com apoio à realização de projetos de infraestrutura e à internacionalização produtiva de capitais brasileiros; 
- Pesquisas nos evidenciam que o Brasil é um país com capacidade produtiva ociosa implantada, não apenas nas suas plantas industriais, como também em máquinas, equipamentos e na inovação tecnológica. Fica cada vez mais claro que diferentes setores carecem de investimentos, como por exemplo, o setor de infraestrutura (ELY, 2015);

- O sistema marítimo brasileiro não é homogêneo. Santa Catarina detém diversos portos e terminais privados que "dividem" relativamente a demanda (desconcentração portuária), com relevância para os complexos especializados na movimentação de cargas conteinerizadas (Itajaí, Navegantes, Itapoá e outros). Já em São Paulo, Paraná e Rio Grande do Sul, observa-se uma concentração da movimentação de mercadorias em um único porto (Santos/SP, Paranaguá/PR e Rio Grande/RS, respectivamente). No Nordeste, Pernambuco e Ceará apresentam novos complexos que estão "retirando" as cargas dos antigos portos, caso de Suape (PE) e Pecém (CE);

Abrindo um parêntese, Moniê (2009) afirma que a contribuição das inovações tecnológicas e institucionais foi importante para a integração da ação de atores cujas lógicas assumem uma feição mais sistêmica, como o demonstra a evolução recente do sistema marítimo portuário mundial.

O expressivo aumento das trocas comerciais propicia aos dispositivos logísticos uma posição central, pois a dispersão dos fornecedores, produtores e consumidores exige uma significativa capilaridade dos sistemas de transporte enquanto a organização da produção em rede supõe uma conexão perfeita entre os nós e vetores (Storper, 2004; Veltz, 1999).

- Nossa malha rodoviária está saturada; consequência do modal de transportes privilegiado em nosso território para a mobilidade de cargas e pessoas - rodoviário - já a partir dos anos 1930 (durante o Primeiro Período Vargas²); e, intensificado no governo de Juscelino Kubitschek (1955-1961). Em detrimento de outros modais de transporte - ferroviário, marítimo, de cabotagem e fluvial - que foram sendo sucateados ao longo do tempo. Observamos uma retomada dos investimentos nesses modais a partir dos anos 1990, principalmente a partir da década de 2000; porém, ainda não suficientes para solucionar os gargalhos existentes;

- Ademais, a partir de 1995, as rodovias que sofreram processo de concessão para a iniciativa privada - com cobrança de pedágio - estão localizadas nos principais eixos econômicos; demostrando, portanto, uma seletividade espacial por parte do capital privado. Consequentemente, as rodovias que, estão sitiadas nas regiões

\footnotetext{
1930 a 1945. Dividido em: a) Governo Provisório (03/11/1930 - 17/07/1934); b) Governo Constitucional (18/07/1934-
} 10/11/1937); e c) Estado Novo (10/11/1937 - 29/10/1945). 
menos aprazíveis ao capital, não recebem os investimentos necessários dos governos federal e estaduais para a manutenção das mesmas. Destacamos ainda que o modal rodoviário responde por cerca de $60 \%$ do volume de cargas transportadas no Brasil. Pelas rodovias brasileiras são transportadas, anualmente, 1,2 bilhão de pessoas, ou seja, 95\% de todo o transporte de passageiros do País; ${ }^{3}$

- O aumento elevadíssimo do número de veículos particulares que trafegam pelas pelos municípios e estradas, no século XXI; contribuindo para a saturação do trânsito das grandes cidades e das principais rodovias brasileiras. Em 2000, o Brasil possuía 29.722.950 veículos; em 2015, esse número saltou para 90.686.936 veículos; ou seja, uma expansão de $60.936 .986(205,11 \%)$ em apenas 15 anos; ${ }^{4}$

- Sobre o transporte público de massa nas cidades brasileiras, observarmos que, a partir dos anos 2000, muitas políticas de ampliação das infraestruturas de transporte público voltaram à tona. Só que desta vez, os projetos de implantação de corredores de ônibus e expansão dos sistemas metroferroviários tornaram-se novos mecanismos de destruição criativa da terra incorporados à lógica capitalista (HARVEY, 2011). A prioridade é para as possibilidades de acumulação de capital por espoliação que engendram (HARVEY, 2004), enquanto as verdadeiras consequências que têm para os sistemas de transporte público não são priorizadas;

- Trens suburbanos e regionais, metrôs e veículos leves sobre trilhos (VLT's) necessitam de vultosos aportes de capital e apresentam resultados expressivos na valorização imobiliária de seus entornos; principalmente quando vêm conectados à implantação de grandes itens arquitetônicos. Por isso, são seletivamente distribuídos em porções já bastante luminosas do território (SANTOS \& SILVEIRA, 2001). Por outro lado, os corredores de ônibus geralmente são menos custosos e estão presente primordialmente em áreas das cidades que ainda almejam valorização imobiliária, sejam os antigos centros degradados ou as outrora periferias urbanas de ocupação já consolidada (SALOMÃO, 2015);

- As novas formas de organização do comércio mundial exigiram estratégias para o sistema de transporte. O Estado brasileiro procura ampliar a participação do setor privado em projetos de infraestrutura, com intuito de expandir as ferrovias e construir expressivos eixos ferroviários; sendo que, parte considerável das inversões, é proveniente dos recursos públicos. Os primeiros resultados demonstram que as

Segundo dados do Instituto de Pesquisa e Pós-Graduação em Administração de Empresas (COPPEAD) da Universidade Federal do Rio de Janeiro.

4 Segundo dados do Departamento Nacional de Trânsito (DENATRAN). 
concessionárias realizaram grandes investimentos em tecnologias de informação e logística para ampliar a capacidade da malha, principalmente, para atender a exportação de commodities. A estratégia de racionalização da malha férrea, com desativação de trechos tidos de baixa densidade, também foi amplamente utilizada.

- Abrindo um parêntese, Julio (2015, p. 8254) destaca que:

Com o aumento da exportação de produtos básicos, principalmente para o mercado asiático, também se observa uma política de transporte no sentido de melhorar a eficiência e diminuir os custos de transporte com vistas ao pacífico, fato evidenciado na iniciativa do Corredor Ásia-Pacifico e na ferrovia Bioceânica entre o Brasil e o Peru.

- Portanto, fica claro que as exportações são base para definição das estratégias para o transporte ferroviário. Contudo, não obstante os projetos do Governo Federal, o setor ferroviário brasileiro ainda não integra todo o país e está voltado apenas para setores muitos específicos;

- Com o objetivo de cooperar com a integração regional na América do Sul, foi criada, no início do século XXI, a Iniciativa para a Integração da Infraestrutura Regional Sul-americana (IIRSA), a qual foi absorvida em 2011 pelo Conselho Sul-americano de Infraestrutura e Planejamento (COSIPLAN). Dentre os Eixos de Integração e Desenvolvimento está o Eixo de Capricórnio do qual fazem parte Argentina, Brasil, Bolívia, Paraguai e Chile. Neste eixo o modal ferroviário possui importante destaque, sobretudo devido a projeto de construção do Corredor Ferroviário bioceânio Paranaguá-Antofagasta ${ }^{5}$, cuja relevância para a integração regional é fundamentada pela perspectiva de novas conexões e fomento à rede de transportes (D. CRUZ, 2015);

- A importância da Petrobras como um ator econômico de grande escala no território nacional, ocasionando diversas modificações espaciais, econômicas e sociais; a partir das atividades de exploração, produção, transporte e distribuição da cadeia do petróleo e gás natural;

- Abrindo um parêntese, sobre o papel da Petrobras no cenário nacional, Souza e Pereira Júnior (2015, p. 8482) afirmam que:

Na busca pela fluidez, o uso do território a partir dos sistemas técnicos produz uma articulação reticular da produção, e por consequência, imprime-se a racionalidade técnica de um segmento produtivo que atua de forma hegemônica, cuja dinâmica territorial instiga a reflexão acerca do papel dos agentes políticos e econômicos na organização do espaço no atual contexto da globalização.

Cidade localizada no norte chileno. 
- O governo federal em suas políticas públicas, como o Estatuto da Cidade, a Política Nacional de trânsito e a Política Nacional de Mobilidade Urbana, entre outras, privilegiam o transporte público e não comtemplam "o transporte de cargas como uma prerrogativa no planejamento e isso acaba se reproduzindo nas políticas municipais" (SILVA e RODRIGUES, 2015, p. 8229). Não obstante, algumas cidades como Cascavel, Curitiba, Porto Alegre e São Paulo apresentam em seus planos a mobilidade de cargas e direcionam a um planejamento que diminui os custos de tempo e espaço;

- Os empregos no Brasil da Era Lula (2003-10), segundo Araújo (2013); Costa e Marin (2015), recuperam dinamismo e diminuíram a taxa de informalidade. Simultaneamente, o desemprego reduziu expressivamente; na contramão das tendências mundiais do mesmo período. Destacamos que, no período de dezembro/2002 a dezembro/2010, é verificado que as regiões Norte, Nordeste e Centro-Oeste lideraram os índices dessa variável; respectivamente com taxas anuais de crescimento de: $8,0 \%, 6,4 \%$ e 5,7\% (2002-2010). Além disso, ressalta-se o número total de novos empregos formais (com carteira de trabalho assinada/direitos trabalhistas) criados no período: mais de 15 milhões;

- A ampliação das exportações brasileiras entre 1999 e 2014 foi caracterizada pela expansão na participação de produtos primários, como resultado do aumento da demanda internacional por commodities e o consequente aumento nos preços desses produtos. Analisando-se a distribuição geográfica dessas exportações, observa-se que o dinamismo é diretamente influenciado pelo território da Ásia. Sobre o recorte temporal selecionado, destacamos que ele procura contemplar o período de superávit comercial brasileiro ocorrido entre 2001-2013;

\section{PARA REFLETIR}

O transporte é premissa importante à circulação do capital. Logo, este também é primordial na produção e reprodução do espaço. A circulação é tão fundamental quanto à produção, "pois somente quando da passagem do produto como mercadoria da esfera da produção para a esfera do consumo é que poderá se efetivar o consumo. Esta mudança, não ocorre, necessariamente, no mesmo lugar, necessitando, portanto de meios e vias para fazê-lo" (ELY, 2015, p. 8216).

Em relação aos Portos, observamos que a política de reestruturação e modernização dos mesmos sitiados no território nacional, iniciada nos anos 1990, precisa ser continuada e aprofundada com a finalidade de torná-los mais eficientes e competitivos. 
Concordamos também com Santos (1997), o qual afirma que a produção da fluidez é, também, um cometimento constituído pela ação do poder público e do setor privado, fundamentado em uma "natureza mista e ambígua"; cabendo, portanto, ao Estado, abastecer o território dos macrossistemas técnicos sem os quais as demais técnicas não se realizam.

Ademais, constamos que apesar dos esforços/avanços do governo federal nos últimos 14 anos na infraestrutura e logística nacionais, o Brasil ainda possui gargalhos significativos nestes setores; dificultando, assim, a construção da nação e cidadania plena. Logo, concordamos com a argumentação de W. Cruz (2015, p. 8181):

Consideramos que prover o território de infraestruturas de transportes é uma das variáveis condicionantes para desatravancar o desenvolvimento nacional, regional e local, juntamente com outras condicionantes; infraestruturas de energia, saneamento; melhoria da saúde pública; erradicação da miséria; políticas para combater as desigualdades regionais e, por último, e não menos importante, investir em educação, pois a mesma teve um desprestígio histórico em sucessivos governos do Brasil.

Portanto, este artigo aponta para a relevância da geografia econômica nas reflexões não esgotadas da temática do "Desenvolvimento Regional e Infraestrutura"; tema esse tão caro aos políticos e governantes brasileiros.

\section{REFERÊNCIAS}

1. ALVES-MAZZOTTI, A. J. A "revisão da bibliografia” em teses e dissertações: meus tipos inesquecíveis - o retorno. In BIANCHETTI, L.; MACHADO, A. M. N. (orgs.). A bússola do escrever: desafios e estratégias na orientação e escrita de teses e dissertações. Florianópolis: EdUFSC; São Paulo: Cortez, 2006. p. 25-44.

2. ANPEGE. Anais do XI Encontro Nacional da ANPEGE. Presidente Prudente: UFGD Editora, 2015.

3. ARAÚJO, Tânia B. de. Desenvolvimento regional brasileiro e políticas públicas federais. In: SADER, Emir. 10 anos de governos pós-neoliberais no Brasil: Lula e Dilma. São Paulo: Boitempo Editorial; Rio de Janeiro: FLASCO Brasil, 2013, p. 157-171.

4. BARRETO, E. S. de S.; PINTO, R. P. Avaliação da Educação Básica (1990-1998). Estado do Conhecimento n. 4. Brasília, DF: MEC/INEP, COMPED, 2001 (Série Estado do Conhecimento no. 4).

5. CHAUÍ, M. A universidade operacional. Revista da ADUNICAMP, Campinas, ano 1, no 1 , jun. 1999.

6. COSTA, P.; MARIN, M. Z. Geografia humana II: leituras sobre o território. Guarapuava: Unicentro/UAB, 2015. 
7. CRUZ, D. A. M. de O. O processo de integração Sul-americana através da IIRSA/COSIPLAN: uma discussão a partir do eixo de capricórnio. Anais do XI Encontro Nacional da ANPEGE. Presidente Prudente: UFGD Editora, 2015, p. 8351-8362.

8. CRUZ, W. L. de M. O complexo portuário do Itajaí: o papel das políticas institucionais, dos investimentos em infraestruturas e das empresas de transportes e logística na dinâmica de movimentação de cargas. Anais do XI Encontro Nacional da ANPEGE. Presidente Prudente: UFGD Editora, 2015, p. 8170-8181.

9. ELY, J. Financiamento do desenvolvimento brasileiro. Anais do XI Encontro Nacional da ANPEGE. Presidente Prudente: UFGD Editora, 2015, p. 8207-8218.

10. FERREIRA, N. S. de A. As pesquisas denominadas "estado da arte". Educação \& Sociedade, Campinas, ano XXIII, nº. 79, p. 257-272, 2002.

11. HADDAD, S. Educação de Jovens e Adultos no Brasil (1986-1998). Brasília: MEC/INEP, COMPED, 2002 (Série Estado do Conhecimento nº. 8).

12. HARVEY, D. O novo imperialismo. São Paulo: Loyola, 2004.

13. . O enigma do capital e as crises do capitalismo. São Paulo: Boitempo, 2011.

14. MONIÉ, F. Desenvolvimento territorial nas cidades-porto da América do Sul. Anais do $12^{\circ}$ Encuentro de Geógrafos de América Latina. Montevidéu: UDELAR, 2009, p. 1-15.

15. SALOMÃO, V. As seletividades dos projetos de ampliação das infraestruturas de transporte público no estado de São Paulo. Anais do XI Encontro Nacional da ANPEGE. Presidente Prudente: UFGD Editora, 2015, p. 8375-8385.

16. SANTOS, M. A natureza do espaço: Técnica e tempo. Razão e emoção. 2 ed. São Paulo: Hucitec, 1997.

17. SANTOS, M.; SILVEIRA, M. L. O Brasil: território e sociedade no início do século XXI. Rio de Janeiro: Record, 2001.

18. SILVA, F. de O.; RODRIGUES, W. F. Logística territorial: comportamentos e limitações de Uberlândia/MG. Anais do XI Encontro Nacional da ANPEGE. Presidente Prudente: UFGD Editora, 2015, p. 8219-8230.

19. SOUZA, D. N. de; PEREIRA JÚNIOR, E. A. A configuração territorial da indústria petrolífera instalada na bacia potiguar: uma análise a partir dos campos de produção e sistemas técnicos da Petrobras. Anais do XI Encontro Nacional da ANPEGE. Presidente Prudente: UFGD Editora, 2015, p. 8472-8483.

20. STORPER, M. Territories, Flows and Hierachies in the global economy. In: BARNES et al. Reading Economic Geography. Oxford: Blackwell, 2004.

21. VELTZ, P. Mundialización, ciudades y territórios. Ariel: Barcelona, 1999.

Artigo recebido em 30 de março de 2016.

Artigo aceito em 30 de abril de 2016. 
